\title{
O PAPEL DO TRADUTOR NA HISTÓRIA: A PERSPECTIVA DA CRÍTICA FRANCESA
}

(1814-1837)

\author{
THE TRANSLATOR'S ROLE IN HISTORY: THE PERSPECTIVE OF FRENCH CRITICISM
}

(1814-1837)

Cristian Cláudio Quinteiro Macedo ${ }^{1}$, Patrícia Chittoni Ramos Reuillard ${ }^{2}$

\begin{abstract}
Resumo: O artigo, no âmbito da historiografia da tradução, apresenta os primeiros resultados de uma pesquisa em andamento sobre a representação da figura do tradutor no século XIX. Para tanto, parte de uma amostra de resenhas críticas de tradução, publicadas no Journal des débats, de 1814 a 1837, período de grandes avanços no mercado editorial francês e de mudanças no pensamento em relação à leitura e ao público leitor. As primeiras análises indicam que a questão fidelidade/infidelidade da tradução em relação ao texto de partida percorre o período, principalmente porque foi nessa primeira metade do século XIX que coexistiram as duas formas de traduzir modelares da cultura letrada francesa: as belas infiéis e a tradução palavra por palavra, que redundou na tradução reconstituição histórica.
\end{abstract}

... de perfectionner son beau travail et de le rendre, de plus digne d'une si auguste approbation et de celle du public, souverain très puissant sur la destinée des ouvrages littéraires.

Abel-François Villemain

O texto em epígrafe foi extraído de uma resenha crítica do Journal des débats, publicada no dia 7 de janeiro de 1824 . Ele retrata uma mudança de postura em relação à produção intelectual e, em especial, à tradução. Nos séculos precedentes, bastava a chancela real ${ }^{3}$ para que uma obra fosse aceita e reconhecida no mundo literário. No século XIX, a aprovação do rei já não era suficiente. Um novo soberano na república das letras havia surgido: o público leitor. Em uma França com a monarquia restaurada, após a queda de Napoleão I, a nobreza não lograva êxito em consolidar, na chamada Restauração, o retorno ao statu quo anterior a 1789, nem em abafar as novas perspectivas em relação à vida, ao mundo e à arte. $\mathrm{O}$ gosto não cederia a decretos reais, tampouco a imprensa retardaria seus avanços.

Nas primeiras décadas no século XIX, as tiragens de livros e jornais só aumentavam. O público leitor se multiplicava, e os burgueses, ligados ao mercado editorial, investiam mais e mais (e lucravam). A figura do tradutor era cada vez mais requisitada, não só para as reedições dos clássicos greco-latinos, mas também para atender a demanda por edições francesas dos romances ingleses tão em voga, fruto da anglomania que se acentuava desde finais do século XVIII.

Nesse ponto, surgem questões históricas que nos interessam: qual era o papel do tradutor nessa sociedade? O que se esperava de seu trabalho? Como eram representadas essas demandas nos escritos da época?

O autor do trecho em epígrafe foi um dos muitos críticos literários que escreveram nesse famoso jornal e se posicionaram como porta-vozes do gosto do público, de suas aspirações, de suas

\footnotetext{
${ }^{1}$ Mestrando em Terminologia, Lexicografia e Tradução do Programa de Pós-Graduação em Letras da UFRGS.

${ }^{2}$ Professora do Programa de Pós-Graduação em Letras da UFRGS.

3 Sobre a política de publicações francesas implementada pelos Bourbon e que teve seu ápice no século XVIII com a estrutura de censores e as distribuições de privilégios para impressão, ver Darton 1996 e 2016.
} 
expectativas. Por essa razão, com o intuito de responder a essas perguntas, realizamos uma pesquisa sobre a representação do tradutor nesse período, cujos resultados parciais apresentaremos no presente artigo. Nossa principal fonte são as resenhas assinadas por esses críticos, em recorte temporal delimitado, de 1814 a 1837.

Iniciaremos o artigo situando o recorte temporal e apresentando o Journal des débats. Depois, faremos um rápido panorama sobre as duas formas de traduzir em jogo no período (les belles infidèles e tradução reconstituição histórica). Por fim, apresentaremos alguns críticos e analisaremos suas resenhas, que podem trazer luz às nossas questões.

\section{Journal des débats e a sessão Variétés}

As razões da escolha dos anos que delimitam temporalmente o trabalho (de 1814 a 1837) dizem respeito à história do próprio jornal que nos serve de fonte histórica, bem como a um fato de relevância para a Historiografia da Tradução.

O Journal des débats foi fundado em 29 de agosto de 1789 por François-Jean Baudouin (1759-1835) e comprado no ano seguinte pelos irmãos Louis-François Bertin (1766-1841) e Louis François Bertin (1771-1842). Tinha na época um caráter eminentemente político. Chamava-se Journal des débats et des décrets, e sua finalidade era publicar as atas da Assembleia Nacional Francesa.

A partir de 1800, o Débats passa a ter um caráter mais cultural, sendo criada uma seção com esse fim, em seu rodapé, chamada feuilleton. Em 1805, após a ascensão de Napoleão I, seu nome muda para Journal de l'Empire. É somente em 1814, com a restauração da monarquia francesa, que passa a ser chamado Journal des débats politiques et littéraires ${ }^{4}$ e aparece em suas páginas a Variétés, outra seção literária, onde as traduções são resenhadas (BERTIN et al., 1889). Nesse ponto, abre-se nosso recorte temporal.

Em 1837, por outro lado, completa-se um ano de publicação de um dos marcos da mudança de perspectiva tradutória na França, a tradução de Le Paradis perdu, de Milton, por François-René de Chateaubriand (MOUNIN, pp. 57-58). Essa data marca então o fim de nosso recorte temporal.

\section{As duas maneiras de traduzir}

Em nosso recorte temporal, eram usuais basicamente duas maneiras de traduzir: de um lado, a já consolidada belles infidèles, que privilegiava o sentido do texto de partida, mas adaptando a forma à língua e à cultura de chegada; de outro, retomava-se aos poucos a "palavra por palavra", baseada na literalidade.

As belles infidèles tiveram supremacia na "era de ouro" da literatura francesa -, séculos XVII e XVIII (BALLIU, 1995, p.15). Ajustando o texto e o "embelezando" conforme a língua e a cultura de chegada, elas "não pretendiam nada mais do que [...] evitar o que desagradava ao gosto de sua época"5 (MOUNIN, 2016, p. 57). Esse padrão começaria a desaparecer no século XIX quando, em 1866, se "inaugurou" um novo "palavra por palavra" com a tradução de A Ilíada, por Leconte de Lisle, que Mounin classifica como tradução reconstituição histórica. Segundo ele, a tradução proposta por De Lisle, não tinha intenções filosóficas ou estéticas, mas históricas. Tratavase "primeiramente de restituir, graças à literalidade mais escrupulosa, as maneiras de pensar, de sentir, de falar, de agir, de viver e de cantar dos autênticos gregos de três mil anos atrás" (ibidem, p. $68)$.

\footnotetext{
4 Durante o retorno de Napoleão I, no chamado Governo dos Cem Dias (de 20 de março a 8 de julho de 1815), o nome Journal de l'Empire aparece novamente na capa do Débats, mas é descartado tão logo o Imperador é derrotado em definitivo.

${ }^{5}$ Todas as traduções das resenhas são de responsabilidade dos autores do artigo. Os originais não constarão aqui por falta de espaço.
} 
Todavia, tanto a extinção de uma maneira de traduzir quanto o surgimento de outra não se dão de forma estanque e ex nihilo. Entende-se que a emergência de determinadas ideias não acontece de forma linear, teleológica, cronologicamente encadeada e logicamente dada. Ideias são frutos de jogos de força, a cada momento atualizados, sem obedecerem a uma destinação preestabelecida, dão-se no "acaso da luta" (FOUCAULT, 1998, p. 28).

Assim, a partir das fontes documentais e da bibliografia contemporânea, pode-se perceber que as belles infidèles foram perdendo força ao longo do século XIX e o novo mot à mot foi ganhando terreno, mas não sem antes coabitarem no mundo editorial. Entre avanços e recuos, a forma de traduzir parecia muito mais uma percepção do tradutor acerca da expectativa do público do que uma simples reprodução de um sistema tradutório dominante:

À medida que o mercado editorial respondia rapidamente às demandas do público, os tradutores parecem ter seguido a tradição das belles infidèles, nadando contra a corrente do literalismo que começava a se impor na Europa no princípio do século XIX. Não hesitavam em mudar títulos, omitir páginas inteiras e introduzir novos elementos, buscando agradar ao leitor e adequar-se à sensibilidade predominante na época. (DESLILE; WOODSWORTH, 1998, p. 223)

É nesse contexto que a obra de Chateaubriand surge, reforçando uma maneira de traduzir que se consolidaria mais tarde, na obra de De Lisle. Já em 1836, ele propunha realizar uma tradução literal, "linha a linha, palavra a palavra, como um dicionário aberto diante dos olhos", o que, segundo ele, seria uma "revolução no modo de traduzir" (MILTON, 1836, pp. VII-XXVI).

A primeira metade do século XIX completa um arco de grandes transformações que tem a França como nação protagonista. As revoluções burguesas trazem uma perspectiva de aceleração do tempo, que Reinhart Koselleck entende como crucial na construção do moderno conceito de história (KOSELLECK, 2013).

François Hartog, assentado na ótica koselleckiana e nos escritos de Chateaubriand, afirma que nesse período se desenhou uma nova experiência de tempo, uma nova "maneira de engrenar passado, presente e futuro ou de compor um misto das três categorias", um novo regime de historicidade (HARTOG, 2013, p. 11). Por sua vez, Mounin entende a emergência da tradução reconstituição histórica como uma "revolução" com causas sociais: "ao homem eterno de uma sociedade teológica e monárquica, sucedeu o homem histórico de uma sociedade burguesa" (MOUNIN, 2016, p. 67). Uma nova concepção da história, uma nova perspectiva de tempo, uma classe se firmando diante de um passado a ser revisto criticamente, tudo isso certamente contribuiu para a construção de uma nova forma de traduzir, um novo regime de tradução.

No entanto, mesmo a obra de Chateaubriand, "um homem entre dois séculos" (HARTOG, 2013, p. 94), importa-nos mais como um marco temporal para nosso trabalho do que uma personalidade de gênio a inaugurar um novo estilo de traduzir. Nosso esforço é em mapear, descrever e analisar as críticas acerca dos textos traduzidos produzidos nesse período, buscando entender melhor as demandas frente ao papel social do tradutor e de seu ofício. Para tanto, a figura dos críticos e suas predileções por uma ou outra maneira de traduzir, expostas nas resenhas críticas, são o que mais nos interessa.

\section{Os críticos e suas resenhas}

A sessão Variétés não era publicada em dias preestabelecidos. Algumas vezes não aparecia por semanas nas páginas do jornal; em outras, era publicada em dias seguidos. As obras traduzidas são recorrentes na sessão, mas poucas tratam especificamente do trabalho do tradutor. É o caso das resenhas selecionadas para o presente trabalho, realizadas pelos mais atuantes críticos do Journal des débats, que serão apresentados, juntamente com suas posições acerca das traduções que avaliaram, a partir de agora.

\subsection{Dussault}


Como jornalista e crítico literário, Jean Joseph Dussault (1769-1824) ganha notoriedade a partir de seus escritos publicados no Journal des débats, do qual era redator. Tido como crítico de "gosto severo", Dussault, segundo escreverá mais tarde seu amigo Féletz, "combatia com força e talento todos os sofismas dos inovadores literários". Foi considerado "o adversário mais formidável das traduções e dos tradutores" (MONFALCON, 1835, p. xvii).

Em 25 de junho de 1814, sua crítica da tradução da obra Le Cid foi publicada na sessão Variétés. O trabalho do tradutor, Auguste Creuzé de Lesser (1771-1839), não agrada ao resenhista. Em sua opinião, "Lesser se vangloriou da fidelidade mais escrupulosa", o que não lhe teria permitido "nem de apagar, nem de maquiar e embelezar" o texto. Dussault confessa não ter lido toda a obra, mas garante que as passagens que leu "carecem de todo estilo [...] correção, harmonia, colorido, falta tudo". Além de apontar as deficiências daquele tradutor fiel, Dussault o compara a outro tradutor da obra, Jean-Charles Léonard Simon de Sismondi (1773-1842), que lhe agradava mais. O crítico aponta as qualidades de seu trabalho: "ele dissimula sua banalidade; suaviza sua rudeza; pole sua grosseria; enobrece os vis defeitos; enfeita os espaços demasiado nus; suprime, acrescenta" (DUSSAULT, 1814, p. 2).

Dussault sugere, desta forma, que o papel do tradutor é adequar o texto ao leitor da cultura de chegada. É embelezá-lo antes de entregá-lo ao público leitor. Acreditando que o estilo é o que conta, Dussault tem um horizonte tradutório ligado às belles infidèles, o que nos faz entender que não era um "adversário dos tradutores e das traduções", mas um crítico duro em relação ao que percebia ser uma tendência crescente à fidelidade ao texto de partida, a seu ver exagerada.

Todavia, para esse crítico, o papel do tradutor se resume a manejar obras técnicas contemporâneas, ou autores sem muita expressão. Os grandes nomes da Antiguidade clássica, em voga desde a Revolução Francesa (DESLILE; WOODSWORTH, 1998, p. 221), não eram passíveis de tradução, pois "quanto mais importante é um autor, mais oferece belezas que são essencialmente intraduzíveis, e menos encontra bons tradutores". Os novos tradutores continuavam tentando traduzir os clássicos porque, "animados pelo pouco sucesso de seus antecessores", "ainda acreditavam que um favor especial das Musas lhes reservara a tarefa de realizar o que os outros não conseguiram fazer". Em última análise, Dussault entendia que eles estavam "seduzidos por seu amor próprio e por sua audácia" ao tentar em vão realizar um bom trabalho. A perfeição da tradução, em sua visão, ficava mais distante "à medida que eles [os tradutores] se apresentam e que se multiplicam" (DUSSAULT, 1815, p. 3).

\subsection{Féletz}

Charles Marie Dorimond de Féletz (1767-1850) era conhecido por se mostrar "constantemente recalcitrante a qualquer inovação literária". Nisard, seu sucessor na Académie aponta-o como um dos "homens distintos que trabalharam para a restauração do senso moral, do gosto, da língua". Seus artigos e resenhas foram selecionados e publicados na obra em três volumes intitulada Mélanges de philosophie, d'histoire et de littérature (LAROUSSE, 1870, p. 193).

Em 28 de setembro de 1814, Féletz resenhou a obra Odes d'Anacréon, traduzida por Jacques Maximilien Benjamin Bins de Saint-Victor (1772-1859). Debruçou-se sobre a segunda edição, mas noticiou a seus leitores que o autor já preparava uma terceira. Iniciou sua resenha escrevendo que "o público distinguiu como uma obra na qual um verdadeiro talento lutou contra uma grande dificuldade" e que triunfou sobre ela. Marcando a posição do público leitor, Féletz afirma que "felizmente o sucesso da tradução de M. Saint-Victor não dependia mais nem das opiniões dos críticos nem dos anúncios dos jornais". Deixava claro, desse modo, que a aprovação do público era o que mais importava no êxito de uma obra (FÉLETZ, 1814, pp. 1-2).

Ao contrário de Dussault em sua expectativa frente às traduções, Féletz enaltecia a fidelidade do translato que, somado à "elegância", e à "harmonia", era a principal qualidade do trabalho de Saint-Victor (ibidem, p. 3). As diferenças entre as concepções de tradução dos dois são explicitadas na resenha, pois ele faz questão de apresentar um debate entre Dussault e Saint-Victor. 
O tradutor, em seu prefácio das Odes, questiona seus críticos da seguinte forma: "não seriam inspirados todos os poetas? Por isso, não se deve traduzir nenhum deles?". Não esperava, Saint-Victor, que "uma voz imponente", no caso a de Dussault, se elevasse diante da questão:

Não, senhor, não se deve traduzir nenhum: não se deve traduzir ninguém, pois meu anátema contra as traduções e os tradutores não se limita aos poetas, ele se estende a todos os escritores, pelo menos a todos aqueles cujas obras têm o mérito do estilo e são marcadas por algum talento na arte de dispor e expressar as idéias. Abandono à turba dos tradutores as obras puramente técnicas, os tratados elementares, os textos sobre as ciências abstratas e positivas, desde que nenhum talento, todavia, se mostre na linguagem e no estilo de seus autores. (ibidem, p. 4)

Em meio ao debate daqueles que considerava dois velhos amigos seus, Féletz se vê obrigado a tomar o partido de Saint-Victor, pois o argumento de Dussault lhe parece "absoluto demais, exclusivo demais" (idem).

Duas escolas se confrontavam naquele momento. Duas maneiras de traduzir se impunham. Dussault não negava, necessariamente, a tradução, apesar de sua dura retórica em relação à "turba de tradutores". Sua crítica estava focada na nova maneira de traduzir que se desvinculava do padrão das belles infidèles, como vimos na sessão anterior.

Passados mais de dez anos, em uma resenha de 3 de julho de 1825, Féletz parece ter relativizado um pouco sua preferência pela tradução mais fiel ao original. Ao tratar da obra Lettre sur l'amitié entre les femmes, précédée de la traduction du Traité de l'amitié, de Cicéron, traduzida por Angélique de Maussion (1772-1851), ele aprova a tradução mesmo que ela se encaixe no padrão belas infiéis.

Por outro lado, os "elogios" de Féletz à tradutora expressam bem a postura sexista do período. O resenhista escreve sobre a recepção da tradução de Maussion: "uma espécie de fenômeno de uma boa tradução de uma obra latina feita por uma mulher havia excitado a curiosidade". Referindo-se ao título da obra, que trazia a Lettre escrita por Maussion antes da obra de Cícero, o crítico estranha que a "obra principal [...], a tradução importante" é apresentada depois. Essa aparente desordem teria uma razão de ser, pois "sabe-se que as mulheres organizam seus pensamentos de acordo com seus desígnios" (FÉLETZ, 1825, p. 3).

Féletz acredita ter desvendado o mistério de Mme de Maussion:

Pensei que, temendo se apresentar como um sábio tradutor de uma obra célebre de um dos maiores escritores da Antiguidade, ela não desejara mostrar que o tímido autor de uma simples carta sobre um tema familiar que interessava particularmente a seu sexo e ocultar depois, por assim dizer, por meio de um anúncio tão modesto, o anúncio mais fastuoso, mais inusitado, sobretudo para uma mulher, da tradução de um Tratado de Cícero. (Idem)

Não teria ocorrido ao resenhista que a tradução da obra de Cícero poderia estar servindo à melhor compreensão da Lettre? Na medida em que esta defendia ser possível existir amizade entre as mulheres, e a ideia contrária vir de uma leitura equivocada da obra de Cícero, a chance de a obra antiga ser acessória ao texto de Maussion é muito grande.

A tradução de Maussion, no ponto de vista de Féletz, é "fácil, elegante, natural”. Ela teria vencido as dificuldades referentes à "extrema diferença dos idiomas e das sintaxes, associada à prodigiosa diversidade das épocas e das mentes", que comumente davam às traduções "uma aparência afetada, forçada, e formas estranhas e inusitadas", e oferecido ao público uma tradução com a "facilidade e a naturalidade de uma obra original". Mas o resenhista faz uma leve ressalva: "Na verdade, ela traduz um pouco livremente o pensamento do autor, sem se preocupar em traduzir todas suas expressões". Ela teria seguido o princípio de Horácio exposto em trecho citado por Féletz: Nec verbum verbo curabis reddere, fidus interpres ("nem fiel tradutor tratares de traduzir palavra por palavra" ${ }^{, 6}$. 
Parece-nos que, mesmo tendo predileção por uma forma específica de traduzir, Féletz entendia que o papel do tradutor era oferecer ao público uma boa tradução, independentemente do método.

\subsection{Villemain}

Abel François Villemain (1790-1870) foi um literato, historiador, tradutor, político e professor de literatura na Sorbonne, a Universidade de Paris. Oriundo de família burguesa, Villemain destacou-se no período da Restauração Monárquica, escrevendo para diversos periódicos além do Débats, como a Revue des Deux Mondes e o Journal des savants. Durante a Monarquia de Julho, foi ministro da pasta de Instrução Pública (DANTÈS, 1875, pp. 1036-1037).

Em 1814, foi premiado pela Académie Française por seu discurso intitulado Avantages et inconvénients de la critique. Tornou-se membro dessa prestigiosa instituição em 1821, quando derrotou Dussault nas eleições. Muitas de suas críticas foram compiladas na obra Discours et mélanges littéraires, de 1823 (VAPEREAU, 1876, p. 2036).

Em 15 de agosto de 1814, é publicada a crítica de Villemain à obra Aphorismes et pronostiques d'Hippocrate, traduzida por Édouard-François-Marie Bosquillon (1744-1814). Nesse ponto nos deparamos com mais um aspecto do papel social do tradutor: Bosquillon serviria "a ciência de modo útil" ao traduzir a obra. Teria, segundo o resenhista, "todas as condições exigidas para o sucesso, uma longa experiência em medicina e um conhecimento profundo do grego". O mérito da tradução de Bosquillon estaria em apresentar o pensamento de Hipócrates "de um modo mais fiel e mais completo", tornando então seu tradutor "digno de associar seu nome aos textos do criador da Medicina e de servir às escolas modernas” (VILLEMAIN, 1814, pp.3-4).

Outro traço do papel social do tradutor explicitado por Villemain está em sua resenha, publicada em 30 de novembro de 1821, do livro Euvres dramatiques de Schiller, traduzido por Amable Guillaume Prosper Brugière, conhecido como barão de Barante (1782-1866). Com sua tradução "imparcial", com um estilo "demasiado marcado do colorido alemão", Barante produz "um monumento útil, um projeto feito com talento, que nos permite julgar uma escola estrangeira, curiosa até mesmo por seus defeitos" (VILLEMAIN, 1821, p.4).

Em 17 de dezembro de 1823 e 7 de janeiro de 1824, Villemain aborda a obra De la nature des choses, de Lucrécio, traduzida por Jean Baptiste Antoine Aimé Sanson de Pongerville (17821870). Da segunda resenha é que recolhemos a epígrafe do presente artigo, mas já no primeiro parágrafo daquela publicada em 1823 ele firma sua opinião sobre o papel do público no mercado editorial: "Hoje em dia, o público, preocupado com interesses sérios, só desvia seu olhar para a literatura quando crê ver algo excelente ou inovador" (VILLEMAIN, 1823, p. 3). A percepção da demanda social seria imprescindível para o êxito de uma empreitada literária.

Villemain expõe uma faceta da tradução - de certa forma já apontada aqui de forma colateral, na passagem misógina de Féletz ao tratar da tradução de Cícero feita por Mme Maussion. A tradução de uma obra clássica dava visibilidade ao tradutor. $\mathrm{O}$ resenhista escreve que, antes da obra em questão, "M. de Pongerville era totalmente desconhecido na república das letras"; a publicação da tradução de Lucrécio mostraria ao mundo "seu talento e sua existência" (Idem).

\subsection{Charles Nodier}

Vinculando-se ao Romantismo, Charles Nodier passa a publicar seus livros a partir de 1801. Começou a colaborar no Débats em 1814, para o qual produziu centenas de artigos. Em 1823, torna-se diretor da biblioteca de l'Arsenal, mantendo uma produção literária intensa e convivendo em um círculo de amigos que contava com Victor Hugo e Alfred de Musset, entre outros (Ibidem, pp. 1487-1488).

Ao resenhar Essai sur Démosthène et sur son éloquence, traduzido pelo barão Pierre Charles François Dupier (1784-1873), Nodier afirma que "o mais alto grau de perfeição que um 
tradutor pudesse atingir consistia em uma fidelidade severa e correta" (NODIER, 1815, p. 2). Essa será sua perspectiva em relação ao trabalho do tradutor ao longo de suas resenhas no Débats. No entanto, sua posição não é intransigente, visto que, da mesma forma que Féletz, ele entende que essa fidelidade severa deve ser negociada em função da clareza da mensagem do texto.

Dupier, segundo ele, usou de uma "exatidão por demais escrupulosa ao autor que ele trazia para nossa língua". O tradutor teria se esforçado em "conservar até o recorte das frases, [...] a construção mecânica de seus períodos"; no entanto, não tendo a língua francesa os mesmos elementos da grega para "unir todos os elementos dos períodos muito extensos", o resultado seria a recorrência no texto de trechos "que não prejudicam absolutamente a clareza, mas que [...] perturbam a harmonia, e que cansam a atenção" (idem). A posição de Nodier é a de quem entende que o papel do tradutor é ser fiel ao original, embora discorde de uma exagerada exatidão, que acaba por prejudicar a leitura. Para ele, "as belezas poéticas e oratórias não são reproduzíveis; elas não se reproduzem necessariamente pela expressão literal" (ibidem, p.3).

Por outro lado, Nodier entende que uma parcela específica do público leitor demanda exatidão. Os helenistas exigiam "que nenhuma palavra do original fosse omitida pelo tradutor". O trabalho de Dupin acabaria por atender "aos leitores mais difíceis" (Ibidem, pp. 2-4).

A tradução dos Salmos, feita por Jean René Sapinaud de Boishuguet (1780-1844), é objeto de uma resenha de Nodier publicada em 21 de outubro de 1818. A questão dos nichos de leitores é retomada. Para o resenhista, o sucesso de uma obra desse tipo só podia ser esperado "em dois tipos de homens, cada dia menos numerosos, os poetas e os cristãos" (ibidem, 1818, p. 3).

Nessa resenha, Nodier apresenta uma ideia que irá desenvolver em outros momentos acerca do papel do tradutor: ele não deve se mostrar demasiadamente no texto. Boishuguet teria sido admirável, por "não ter buscado ser mais poeta do que seu modelo", por "ter admitido nos dizer com simplicidade o que é simples" (ibidem, p.4).

Em 1822, escreverá: “o tradutor que será mais esquecido, de tanto se identificar ao autor que ele interpreta, será necessariamente aquele que melhor o traduziu". Em sua opinião, a obra que melhor expressa essa condição é a tradução que Barante fez da obra de Schiller, resenhada por Villemain (ibidem, 1822, p. 4).

Em 1837, Nodier traduz a obra Le Vicaire de Wakefield: era sua chance de mostrar na prática sua visão de tradução. $O$ crítico apresentado na próxima sessão do artigo foi o responsável por analisar esse trabalho.

\subsection{Philarète Chasles}

Victor Euphémion Philarète Chasles (1798-1873) foi contratado em 1823 pelos irmãos Bertin, proprietários do Débats, para o qual ele escrevia artigos e resenhas críticas, principalmente de obras em inglês. Segundo Larousse, "os trabalhos críticos de M. Chasles serviram não somente ao conhecimento mais aprofundado das literaturas comparadas da Europa, mas também à formação do gosto francês" (LAROUSSE, 1867, p. 1046).

Em 13 de julho de 1831, Philarète Chasles tem publicada no Débats sua resenha da Bíblia, traduzida por Samuel Cahen (1796-1862). A tradução do original, até então maciçamente traduzido da Vulgata de São Jerônimo, era "uma ação audaciosa". A tradução de Cahen se caracterizava por "uma profunda concisão e uma cor bem oriental", fruto não de uma "elaboração artificial do estilo", mas somente da literalidade, abrindo mão "desses termos que lembram sem cessar ao leitor os costumes de sua Europa". No entender do resenhista, uma tradução "tão útil" só poderia ter sido feita movida pelo "amor à verdade e à ciência" (CHASLES, 1831, p. 3-4).

A tradução de Nodier da obra Le Vicaire de Wakefield, do escritor irlandês Oliver Goldsmith, foi resenhada por Philarète Chasles. Publicada em duas partes, em 5 de julho e 24 de agosto de 1837, sua resenha apresenta uma interessante situação, um crítico de tradução tendo o seu trabalho criticado. Nodier, nessa época, já era um escritor célebre, com uma sólida carreira literária. 
O resenhista havia publicado, no ano anterior, sua tradução de três peças de William Shakespeare (O mercador de Veneza, Ricardo III e Romeu e Julieta).

Philarète Chasles afirma conhecer outras oito traduções da obra Le Vicaire, onde "abundam contrassensos". A penúltima tradução, escreve, contém "ao menos um erro grosseiro em cada duas páginas; erros contra o bom senso, contra o dicionário, contra o pensamento de Goldsmith" (CHASLES, 1837, p. 4).

Não há agressividade na escrita do resenhista em relação à tradução de Nodier, mas há alguns elementos bem significativos em sua apreciação. Ele diz acreditar que ambos, autor e tradutor, são "dois espíritos gêmeos que fazem bem em caminhar juntos", que os dois possuem uma "flor de afabilidade e de elegância". Mas, após o elogio, Philarète Chasles escreve:

A única crítica que se pode fazer a essa encantadora cópia de um excelente modelo é ser uma cópia algumas vezes um pouco mais concisa e um pouco mais trabalhada que o original [...] Se por vezes M. Nodier supera em elegância o autor que lhe serve de modelo, sob essa elegância sempre se esconde um sentimento refinado da ingenuidade de Goldsmith. (Idem)

Ao que parece, o tradutor Nodier abriu mão da "fidelidade severa e correta" proposta pelo Nodier crítico.

\section{Considerações finais}

As resenhas consultadas até aqui, focadas a partir das questões norteadoras de nossa pesquisa - sendo a principal Qual era o papel do tradutor? -, dão interessantes pistas sobre as expectativas em relação ao tradutor e sobre a realidade que se desenhava no período estudado. Um período de grandes avanços no mercado editorial e de mudanças no pensamento em relação à leitura e ao público leitor.

Vimos que a questão fidelidade ou infidelidade percorre o período, principalmente porque foi nessa primeira metade do século XIX que coexistiram as duas formas de traduzir modelares da cultura letrada francesa: as belas infiéis e a tradução palavra por palavra, que redundou na tradução reconstituição histórica.

Na perspectiva dos críticos literários, lidos nas páginas do jornal diário, o papel do tradutor variava entre simplesmente apresentar uma obra de qualidade, independentemente da sua maneira de traduzir, servir à ciência, documentar uma escola literária estrangeira, atender aos diferentes nichos do público leitor.

Obviamente, trata-se de uma primeira abordagem da documentação, percorrendo a representação do crítico literário frente à realidade vivida naquela sociedade. Mas, independentemente da demanda do crítico, percebemos situações históricas irreversíveis que devem ser levadas em conta em qualquer análise acerca do papel do tradutor naquele contexto: o público leitor tornava-se importantíssimo no processo editorial, e os tradutores entravam em massa no mercado cada vez mais ávido por suas produções. Como escreveu um Dussault contrariado, eles se multiplicavam, formavam uma "turba" que traduzia todo tipo de texto e, a despeito da crítica, produzia traduções de enorme contribuição cultural para os leitores francófonos.

Por ser uma pesquisa em andamento, os resultados aqui apresentados ainda são parciais, buscando dar um panorama do posicionamento acerca do papel social do tradutor na França oitocentista, de importantes críticos literários. À medida que avançarmos em nossa análise documental, mais sólida será a contribuição a um importante ponto da Historiografia da Tradução: a história do próprio tradutor e sua relevância cultural, econômica, política e social ao longo do tempo.

\section{Referências bibliográficas}


BALLIU, Christian. Los traductores transparentes. Historia de latraducción em Francia durante el período clásico. Hieronymus Complutensis, n.1, p. 9-51, 1995.

BERTIN, Ernest; BOURGET, Paul ; CHAILLEY, Joseph et al. Le Livre du centenaire du Journal des débats. Paris: E. Plon, Nourrit et Cie, 1889.

CHASLES, V. E. P. Le Vicaire de Wakefield (I). Journal des débats. Paris: 5 jul. 1837, Variétés, pp. $3-4$.

. Nouvelle traduction de la Bible. Journal des débats. Paris: 13 jul. 1831, Variétés, pp. 3-4.

DARTON, Robert. O Iluminismo como negócio: história da publicação da Enciclopédia (1775-

1800). Tradução: Laura Teixeira Motta e Maria Lucia Machado. São Paulo: Companhia das Letras, 1996.

. Censores em ação: como os estados influenciaram a literatura. Tradução de Rubens

Figueiredo. São Paulo: Companhia das Letras, 2016.

DANTÈS, Alfred. Dictionnaire biographique et bibliographique, alphabétique et méthodique, des hommes les plus remarquables dans les lettres, les sciences et les arts, chez tous les peuples, à toutes les époques. Paris: Boyer, 1875.

DESLILE, Jean; WOODSWORTH, Judith (Org.). Os tradutores na História.Tradução de Sérgio Bath. São Paulo: Ática, 1998.

DUSSAULT, Jean Joseph. Le Cid, romances espagnoles, imitées en romances françaises. Journal des débats. Paris: 25 jul. 1814, Variétés, pp. 1-4.

pp. 2-4.

. L'Iliade d'Homère, traduction nouvelle. Journal des débats. Paris: 10 dez. 1815, Variétés,

FÉLETZ, Charles-Marie de. Lettre sur l'amitié entre les Femmes, précédée de la traduction du Traité de l'amitié, de Cicéron. Journal des débats. Paris: 3 jul. 1825, Variétés, pp. 3-4. Mélanges de philosophie, d'histoire et de littérature. Paris: Perisse frères, 1840.

. Odes d'Anacréon. Journal des Débats. Paris: 28 set. 1814, Variétés, pp. 1-4.

FOUCAULT, Michel. Nietzsche, a genealogia e a história. Tradução de Marcelo Catan. In: Microfísica do poder. 1998. Rio de Janeiro: Graal, pp.15-37.

FURLAN, Mauri. Ars traductoris: questões de leitura-tradução da Ars poetica de Horácio (dissertação de mestrado). Florianópolis: UFSC, 1988.

HARTOG, François. Regime de historicidade: presentismo e experiências do tempo. Tradução de Andréa Souza de Menezes, Bruna Beffart, Camila Rocha de Moraes, Maria Cristina de Alencar Silva e Maria Helena Martins. Belo Horizonte: Autêntica, 2013.

KOSELLECK, Reinhart. O conceito de história. Tradução de René Gertz. Belo Horizonte: Autêntica, 2013.

LAROUSSE, Pierre. Grand Dictionnaire universel du XIXe siècle. Tomo 3. Paris: Administration du Grand Dictionnaire universel, 1867.

. Grand dictionnaire universel du XIXe siècle. Tomo 8. Paris: Administration du Grand Dictionnaire universel, 1872.

MILTON, John. Le Paradis perdu. Traduction nouvelle, par M. de Chateaubriand.Tomo 1. Paris: Furne et Charles Gosselin, 1836.

MONFALCON, J. B. Essai sur la vie et les ouvrages d'Anacréon. In: ANACRÉON. Odes. Paris: Didot, 1835, pp. xi-xix.

MOUNIN, Georges. Les Belles infidèles. Villeneuve-d'Ascq: Presses Universitaires du Septentrion, 2016.

NODIER, Charles. Chefs-d'œuvre des théâtres étrangers. Journal des débats. Paris: 2 jan. 1822, Variétés, pp. 3-4. 
. Essai sur Démosthène et sur son éloquence. Journal des débats. Paris: 5 abr. 1815, Variétés, pp. 1-4.

. Les Psaumes traduits en vers français. Journal des débats. Paris: 21 out. 1818, Variétés, pp. 1-4.

VAPEREAU, Gustave. Dictionnaire universel des littératures. Paris: Hachette, 1876.

VILLEMAIN, Abel François. Aphorismes et pronostiques d'Hippocrate. Journal des débats. Paris: 15 ago. 1814, Variétés, pp. 3-4.

. Euvres dramatiques de Schiller. Journal des débats. Paris: 30 nov. 1821, Variétés, pp. 3-

4.

. De la nature des choses (I). Journal des débats. Paris: 17 dez. 1823, Variétés, pp. 3-4.

. De la nature des choses (II). Journal des débats. Paris: 07 jan. 1824, Variétés, pp. 3-4. 